\title{
Collaboration as an Essential Key to Education for Sustainable Development
}

\author{
Seema, Mahima Gupta
}

\begin{abstract}
Sustainable Development deals with issues like climate change, disaster risk, biodiversity, poverty, environmental degradation, pollution, overconsumption, gender inequality, health, quality education and economic growth. As evident from the 17 Sustainable Development Goals, every aspect of natural, social and economic field has become an area of concern for sustainability at local as well as global level. Collaboration promotes peace worldwide and brings effectiveness and accountability at institutional level. This would facilitate their contribution towards sustainability as an underlying force towards sustainable development. Human settlements with fast growing industrialization have to keep balance with other forms of life on the planet and also with its natural resources. Education serves as a basis to sustainable development as it is through education only that global citizens can be created who have the competencies to sustainable development now and in the future. Education for sustainable development requires coordination and collaboration among all these different fields and they all must support education. People and organizations from diverse fields need to come together and make collaborative efforts in education for sustainable development. In the present paper, an attempt has been made to throw light on the need and importance of collaboration and interrelation of education sector with various other sectors of society such as economics, business, health, environment and legal framework.
\end{abstract}

Index Terms: Collaboration, Education for Sustainable Development (ESD), Global Citizens, Sustainability, Sustainable Development Goals (SDGs).

"All the SDGs come down to education..."

- Malala Yousafzai

\section{INTRODUCTION}

Education is the foundation to sustainable development. Quality Education is the fourth among 17 Sustainable development Goals (SDGs), in which United Nations Educational, Science and Cultural Organization (UNESCO) leads and acts as a specialized agency for education and coordinates the 2030 agenda. Sustainable Development Goal (SDG) 4: Quality Education, is aimed at ensuring inclusive and equitable quality education and promoting lifelong learning opportunities for all. Education for Sustainable Development (ESD) fulfills and satisfies the basic educational needs that create the abilities and competencies in the learner to experience a balanced living socially, culturally and economically. New skills, values and attributes are required to be developed in the learners in $21^{\text {st }}$ century that can lead to sustainable cities and societies. Education system

Revised Manuscript Received on July 5, 2019

Ms. Seema, Amity Institute of Education, Amity University, Noida, UP, India,

Dr. Mahima Gupta, Associate Professor, AIE, AUUP, NOIDA, India must respond to this urgent need by transforming learning objectives, learning content and introducing new pedagogies that can empower the learner and inspire the institutions to inculcate sustainability principles in their operational systems. Education has the responsibility to prepare the citizens for $21^{\text {st }}$ century who can face the challenges of this fast-changing world and to foster the right type of values and skills that prove helpful in sustainable development. ESD aims at developing competencies that empower learners to become Global Citizens who think critically and act in accordance of their prevalent and forthcoming cultural, socio-economic and environmental impacts from local as well as global perspective, in a sustainable manner.

\section{ESD: INTEGRATED AND MULTIDIMENSIONAL}

People must understand the complex world where they live and be able to collaborate and act as sustainable citizens. Agenda 21 urges all the nations to develop and implement a strategy on ESD in both formal and non-formal systems of education at all stages of it. Primary and secondary education must exhibit the most progress in incorporating sustainability in their curricula and teaching-learning strategies. About $40 \%$ of Member States claim to have integration of ESD into their formal curricula. Education serves as a goal in itself as SDG4 and also a means to achieve all other SDGs.

Some Example:

The Maurice lle Durable policy in Mauritius (2008), aims at making it a world model of sustainable development by the year 2020 and because of this project, ESD has been addressed by many formal and non-formal institutions and organizations.

Finland is also reforming its national core curricula for preschool and basic education to support and promote ESD for a sustainable future.

Manitoba, Canada has ESD integrated into the curricula and it has been an area of prime action for the government from kindergarten to $12^{\text {th }}$ grade. Such an integrated education helps schools to embed sustainability concepts into their classrooms, administration and management systems.

Japan and Germany have been countries where the notion of ESD resonates strongly with local stakeholders where principles of sustainability are inherently learnt by the students at right from a younger stage.

South Africa, here case studies have shown community-based learning for sustainability, and communities seek to pursue new educational activities which are far more just economically, socially and environmentally paving way to overall sustainable development.

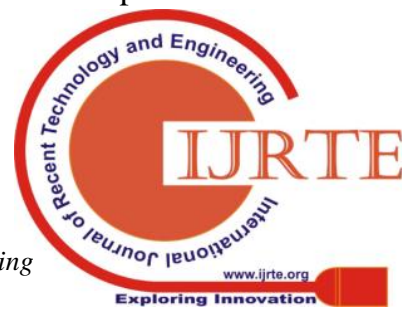


ESD calls for a balance between the economic, social and environmental dimensions of sustainable development. It requires acknowledgement of the inter-linkages between these dimensions. Integration of these different dimensions refers to a systematic and holistic approach with interconnections between education and other sectors of development. Failure in integration among various sectors with education would result in insufficient recognition and understanding that ultimately results into incoherent, inconsistent policies and other associated impacts. An integrated approach to ESD takes advantage of synergies across various sectors and is impossible to achieve through isolated or single sectoral approach.

Integration among diverse sectors requires greater alignment of resources, strategies and planning at both local and global levels for a more comprehensive approach to sustainable development. This approach would shape incentives for integrated conceptualizations, funding, planning and implementation of development programmes.

It has become imperative for governments and government departments, non-government organizations and other important agencies, communities, families and influential persons to come together to endorse and support education system in order to achieve quality in education which is one of the goals of sustainable development (SDG-4).

United Nations' Sustainable Development Fund (SDG-F), established in 2014, is the international agency which supports sustainable development activities through integrated, multidimensional joint ventures and projects.

\section{COLLABORATION IN ESD}

In educational scenario, collaboration is seen as a teaching-learning approach that involves groups of learners working together for common goals. The learners have their own perspectives and ideas that must be put together, articulated and shared for mutual benefits in order to achieve the target. Collaborative learning provides the learners with opportunities to discover new opportunities to communicate, exchange, present or defend their ideas and take appropriate actions that promote the success of their shared goals. In this process, learners have to work together co-operatively and not competitively.

In this way collaborative learning becomes a fundamental learning approach to ESD, wherein every partner has responsibility and accountability for the results or outcomes. In the traditional concept of collaboration, it is viewed as a philosophy of interaction and intercommunications where individuals are held responsible for their actions and respect each other's abilities and contributions to achieve some objectives. It shares the authority and responsibilities of group members in the pursuit of a common goal. ESD, in a collaborative sense will require a shift from teaching to learning and dealing with problems to find their solutions by critical thinking and involves active working and by each member. Collaborative learning develops interpersonal dynamics to promote, encourage or assist others in the group for completion of the task. In this way, learners develop critical thinking and a culture of positive interdependence and various other social skills like leadership, decision-making, communication, trust building and conflict management which are important aspect of ESD. The 21st century need in society is to think and work together on critical issues of sustainability and it demands shifting from individual work to collaborative work to solve sustainability problems at all levels.

Collaborative learning (CL) can be considered as a promising mode of learning for achieving sustainable development goals for it:

- provides a social frame and support system for learners.

- helps to build mutual understanding among learners.

- inculcates cooperation among learners rather than competition.

- develops self-esteem and positive attitude towards each other.

- promotes critical thinking, problem solving and decision-making skills.

Clearly, our sustainable future advocate's application of collaborative learning in educational institutes at all stages of education from local to global level, providing more positive heterogeneous relationships and diverse understanding. It fosters a supportive learning environment for ESD, resulting in higher achievement and greater productivity

\section{USE OF INTERSECTORAL APPROACH IN ESD}

The inter-sectoral approach must be employed in achieving sustainable development goals by means of education to counter the challenges of sustainable future and to create a conducive environment within which countries and development partners come together for planning and implementation of sustainable goals.

The Sustainable Development Goals Fund (SDG-F), created by United Nations Development Fund (UNDP) in 2014 with support from Government of Spain, supports sustainable development through integrated and multidimensional joint programs. It operates in 18 countries covering the following thematic areas:

- Eradication of Poverty

- Security of Food and proper Nutrition

- Availability of Pure Water and Sanitation

In addition to these sectors, gender equality, women empowerment, agricultural production and health sector also make pre-requisite for incorporation with education sector for sustainable development.

In addition to cognitive skills that education tends to develop in the learners, several non-cognitive skills and a set of key competencies must be developed in the learners for providing ESD. These skills and key competencies can better be developed systematically by collaborating with other sectors. For instance, entrepreneur skills can be imbibed by the learners while contributing in an enterprise actively rather than theoretical explanations. This can be possible when industries and other organizations collaborate with education sector.

Published By: 
Multi-dimensional programs that involve active participation of diverse sectors and fields of socio-economic world need to come up with education sector to plan, implement and coordinate shared activities with learners so that learners can have first- hand experience by contributing towards activities for sustainable development and develop a healthy and positive attitude towards the sustainability of this planet which is fundamental to their actions, today and in future.

A participatory approach is required to operate through joint programs where agencies, ministries, NGOs, and private sectors from different dimensions collaborate to create integrated joint programs with educational institutes of all levels from kindergarten to higher education.

The implementation of ESD at local, national and international level has interconnections with diverse fields and it has become essential to emphasize partnership among institutions and multiple stakeholders to take up co-learning and collaborative learning.

Collaborative learning for sustainable development should be based upon certain principles that contribute to the success of these collaborative programmes and make them effective. In collaborative practices, individual benefits are as important as the overall success of the mission. It should take up a strategic analysis before taking up technological advancements and should lead by example. Each participant or stakeholder must integrate to the flow of the work and create a supportive environment. Collaborative actions must be persistent, adaptive, and evolutionary to make the world a better place to live. ESD requires collaborating with diverse sectors to take advantage of providing practical knowledge and skills and for behavioral modification of learners of $21^{\text {st }}$ century who in turn will support sustainability on this planet.

This has to be a mutual adventure incorporating and involving various sectors of the society and participating actively into the education sector. Such a collaborative approach in education has clear advantages of avoiding or reducing overlap between development programs. The inter-sectoral and multidisciplinary approach increases coordination among governments and development partners and prevent competition for funds.

Sharing of common but differentiated responsibilities depending upon cultural and social contexts is need of the hour. Climatic and sustainability issues are given utmost attention these days worldwide and India has become a leading nation among the developing world for taking up necessary action and addressing these issues in its policies.

"The principle of common but differentiated responsibilities is the bedrock of our enterprise for a sustainable world" Shri Narendra Modi, Prime Minister of India

A lot of financial and technical support is needed by the developing countries that should be provided by the developed world in order to make this planet sustainable to support humanity and life. But, developing countries, nonetheless can be the leaders in sustainable development in their own ways to achieve the goals in perspective of their own socio-cultural needs and by having an independent, self-supporting vision for their future. There must be a paradigm shift in education that can take it beyond the boundaries of educational institutions and make collaborative relationships and endeavors with other prime organizations and establishments

\section{CONCLUSION}

ESD is a global mandate and governments from all over the world need to subscribe to it. The policies and objectives of education at global as well as local levels should implement ESD ranging from kindergarten to higher education. Governments, NGOs, enterprises, municipalities, industries and private organizations must collaborate and showcase exemplary ESD practices to inspire populations and communities at other parts of the world and should lead to further activities. The collaborative approach incorporating multi-sectoral and multidimensional arena has to start from grassroots level and must be upgraded to global level to address and resolve the issues related to sustainability. The coordination of the actions in collaborative way by different sectors along with education would provide guidance for the upgrading of ESD in learning communities whether these communities are local, national or at the global level. Learning from an ESD perspective, in true sense must be a collaborative learning process which focuses on simultaneous cultivation of diversity and differences with similarities in its own way keeping in view of the local culture and society and integrating up to global level. Creating and developing joint ownership, unfolding creativity and dynamic energy to break with existing patterns, routines or systems and co-create their own solutions with governments, NGOs and educational institutions that would give way to sustainable development.

\section{REFERENCES}

1. Schools in action, global citizens for sustainable development: a guide for students (PDF). Paris:UNESCO.2017.ISBN 978-92-3-100179-6.

2. "Shaping the Future We Want. UN Decade of Education for Sustainable Development (2005-2014). Final Report” (PDF). UNESCO. 2014.

3. Fricke H., Cathryn, G., Skinner, A. 2015. Monitoring Education for Global Citizenship: A Contribution TO Debate. Brussels, DEEEP CONCORD DARE $\quad$ Forum. Available at:http://unesdoc.unesco.org/images/0023/002329/232003e.pdf

4. United Nations (UN).2015. Sustainable Development Goals. Available at:

http://www.un.org/sustainabledevelopment/sustainable-development-g oals

5. UNESCO. 2015a Education 2030. Incheon Declaration and Framework for Action, Towards Inclusive and equitable Quality Education and Lifelong Learning. Paris, UNESCO. Available at: http://unesdoc.unesco.org/images/0023/002329/232993e.pdf

6. Education for Sustainable Development Goals: Learning Objectives (PDF). Paris:UNESCO.2017.

7. Rethinking Education: Towards a global common good (PDF) UNESCO. 2015.ISBN 978-92-3-100088-8

8. Dernback, J.C. (2002) Stumbling towards sustainability.

9. Huckle, J. and Sterling, S.R. (2006) Education for sustainability. Earthscan.

10. "The UN Decade of Education for Sustainable Development 2005-2014". UNESCO.

11. "Global Citizenship Education: Topics and learning objectives" (PDF) UNESCO.2015.

12. "Transforming our world: the 2030 Agenda for Sustainable Development. Resolution adopted by the General Assembly on 25 September 2015". United Nations. 2015.

13. Woods (1 January 2003)." Environmental Education for a sustainable future: formal schooling". Curriculum.edu.au 
14. Schools in action, global citizens for sustainable development: a guide for students (PDF). Paris: UNESCO.2017. ISBN 978-92-3-100179-6.

15. Teaching and Learning for a Sustainable future: A multimedia teacher education program." UNESCO.2010.

16. Schools in action, global citizens for sustainable development: a guide for teachers. Paris: UNESCO.2016. ISBN 978-92-3-100180-2.

17. "Shaping the future, we want. UN Decade of Education for Sustainable Development (2005-2014). Final Report". UNESCO. 2014.

18. NEP2016/ReportNEP.pdf

19. Singh H. "Education for sustainable development". Vol. 1. ISSN 0975-1254.15 Jan 2010.

20. "CAT Education and Life Long Learning". Learning.cat.org.uk.

21. Education for Sustainable Development and Global learning (PDF)

\section{AUTHORS PROFILE}

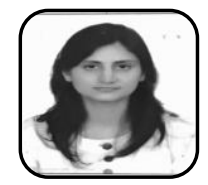

Ms. Seema

Research Scholar

Amity Institute of Education

Amity University, Noida, UP

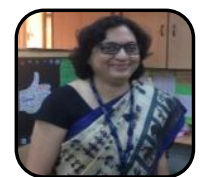

Dr. Mahima Gupta

Associate Professor

AIE, AUUP, NOIDA 